\title{
Nonwovens with and without Super-absorbents Surface Help Firefighters as Additional Active- Cooling to Prevent Heat-Related Deaths
}

\author{
Sebastian Micus ${ }^{1,2, *}$, Hans-Helge Böttcher ${ }^{1}$, Sibylle Schmied ${ }^{1}$, Michael Haupt ${ }^{1}$, Götz T. Gresser ${ }^{1,2}$ \\ ${ }^{1}$ German Institutes For Textile and Fiber Research Denkendorf, (DITF), Denkendorf 73770, Germany \\ ${ }^{2}$ Institute For Textile and Fiber Technologies (ITFT), University of Stuttgart, 70569 Stuttgart, Germany
}

*Corresponding author: E-mail: sebastian.micus@ditf.de; Tel.: (+49) 711-9340 381

DOI: $10.5185 /$ amlett.2020.081545

\begin{abstract}
A drawback of the Personal Protective Equipment (PPE) providing firefighters protection under extreme conditions is their insufficient dissipation of heat and sweat. As a result the body core temperature increases to dangerous levels. At the German Institutes for Textile and Fiber Research Denkendorf (DITF), intensive research is being conducted on cooling materials to protect firefighters from heat related deaths. For this purpose, an active water cooling textile, consisting of different layer constructions and absorption materials has been developed. The cooling mechanism is based on evaporation of the stored water in the absorption material. Two different constructions (an open and a closed system) with various nonwoven water absorption structures, which have been integrated into a textile layer structure, have been developed. We used superabsorbents polymer fleeces and natural viscos fleeces with different weights. In preparation the exact grammage and the absorptive capacity were measured. In addition we visualized the stream in the air-conveying layer. As main test method a special thermos-physiological measurement system has been used to measure the cooling ability of the different layer constructions. Moreover possible cooling effects can be calculated.
\end{abstract}

\section{Introduction}

Firefighters have to perform constantly under extreme environmental conditions such as high air temperatures, high radiation intensities and heavy smoke formation. In particular, offensive firefighting operations create dangerous working conditions for firefighters and require trained physical resilience and functional clothing that protects firefighters against external heat sources. However, the layer structure of the personal protective equipment (PPE) against ambient heat and moisture impairs the permeability of the body's own heat and perspiration to the environment via the skin. This leads to an increasing body core temperature, which can drastically reduce the performance of firefighters and even lead to heat related deaths.

If the core body temperature rises, the concentration capacity decreases very strongly and the error rate in performing activities increases exponentially, which can have serious consequences and thus endanger human life [1]. About $80 \%$ to $90 \%$ of accidents in the field are due to human error and due to incorrect assessment of the situation [2]. It should be added that the core body temperature of firefighters in full equipment increases already at moderate ambient temperatures [3]. It is assumed that most of the accidents happen due to heat stress. American statistics show that $53 \%$ of the recorded accidents in 2014 of firefighters occurred during firefighting operations [4]. Less than $10 \%$ were caused by burns, but more than $25 \%$ by overexertion. Cardiovascular causes account for almost $40 \%$ of fatal accidents, of which more than $75 \%$ were caused mainly by heat stress during firefighting [5]. In order to lower the body core temperature and thus reduce heat stress and not to impair the physical performance of firefighters during firefighting operations, cooling elements are required to absorb the body heat.

Textile cooling systems are divided into three classes. Air-cooled clothing, water-cooled clothing and phase change clothing. Depending on the activity to be performed, a different cooling system has to be selected [8]. Moreover it can be distinguished into active and passive cooling clothes.

Active cooling clothing is divided into two categories, air-cooled clothing and liquid-cooled clothing. The cooling mechanism operates by circulating cold air or distributes liquids in tubes through the clothing. Aircooled systems work with cold, dry air that blows on the body and extracts heat. The body is cooled by the evaporation of sweat on the skin. Convective heat exchange is also improved by increasing the air velocity at the skin surface. Air is supplied by a compressor and controlled by a valve. Most air-cooled systems consist of two layers, an outer layer of impermeable fabric and an inner layer of air-permeable material. Dry air is passed between two layers and is released to the skin surface through the inner layer. The impermeable nature of the 


\section{Advanced Materials Letters www.vbripress.com/aml}

outer layer prevents air from escaping into the environment. Previously, spacesuits used this mechanism. The disadvantages, however, are a very limited cooling capacity due to the low heat capacity of air and a continuous power supply is required. These systems are usually heavy and bulky, so they have some restriction in comfort. Increasing the cooling capacity subsequently leads to unpleasant wind and noise levels [6].

Liquid cooling clothing is currently the most commonly used active cooling clothing. The high heat capacity of water compared to air offers certain technical advantages such as reduced pumping capacity and smaller volume. Mostly a three-layer structure is used, where the tubes are inserted between the inner and outer fabric layer. The sweat is removed from the inner layer in liquid or vapour form.

One of the disadvantages of liquid-cooled clothing is that they require a very tight fit. Also, water leakage can cause problems such as, short circuits, steam burns and discomfort associated with wet clothing.

The passive cooling garments are mainly divided into two groups. They are cooled either with a phase change material or by evaporative cooling.

Phase Change Material (PCM) describes a material which undergoes a phase change at a defined temperature range. A large amount of energy is stored and released in the process. When the material changes from solid to liquid and vice versa, heat is absorbed or released [7]. It should be taken into account that some of the PCMs are not suitable for an environment that is in direct contact with fire (e.g. fire fighters). This is due to the flammable structure of the materials used [8].

INUTEQ PAC offers a cooling vest in three different temperature levels. The biobased PCM consists of polyether or thermoplastic polyurethane (TPU). They have higher flash points than paraffin equivalents. It is $20 \%$ lighter than water and should cool for one to four hours. The packages are cooled at a lower temperature until they are completely solid [9].

The disadvantage of the evaporation technology is that it dries very quickly in the sun or in a dry breeze, even though it is completely saturated with water. Sticking the water-soaked fabric to the body gives an uncomfortable feeling. The development of superabsorbents polymer particles has made the evaporation cooling method easier and cheaper to produce.

The great advantage lies in its small weight and the high comfort in wearing. However, this type of clothing is not suitable for humid conditions, as the effectiveness of evaporative cooling is inversely proportional to the relative humidity of the environment. Another limitation of this technology is that cooling takes place on the outside of the garment, not on the inside, which is closer to the skin [6].

HyperKewl ${ }^{\mathrm{TM}}$ Products use a specific chemistry to achieve rapid absorption and stable water retention. The chemical formulation also improves evaporation. However, this type of clothing is not suitable for humid conditions, as the effectiveness of evaporative cooling is inversely proportional to the relative humidity of the environment. Another limitation of this technology is that cooling takes place on the outside of the garment, not on the inside, which is closer to the skin [6].

HyperKewl ${ }^{\mathrm{TM}}$ Products use a specific chemistry to achieve rapid absorption and stable water retention. The chemical formulation also improves evaporation. The cooling effect should last five to ten hours.

The Rev'it vest is intended for use by motorcyclists. It is soaked in water and is worn under the motorcycle jacket. When the ventilation openings of the jacket are opened, an air flow is created between the jacket and the vest. The cooling effect should last six to ten hours. Temperatures should be reduced by six to twelve degrees compared to the ambient temperature [10].

Together with unico-swiss-tex for MS patients, EMPAEmpa developed a cooling garment made of three layer laminates, which has a two layer absorbent PES fabric in the middle and a waterproof but breathable PES membrane on both sides. The skin temperature can be reduced by up to $5^{\circ} \mathrm{C}$ for over an hour. The membranes are waterproof, breathable composite layers. The created cavity is filled with 20 to $60 \mathrm{ml}$ of water. On the outside, the water evaporates and a cooling effect occurs. Once the water has evaporated, it can be refilled as often as required. A normal syringe is used to fill the clothing. The clothes can be washed in the washing machine [11].

Cooling function textiles of leading sports and occupational safety brands use a special superabsorbent fleece from BASF AG. Fibers of this nonwoven are coated with superabsorbent molecules by a special technology. They absorb the water in a few seconds and hold it. These textiles can absorb ten times its weight in water and at the same time create an almost dry outer layer [12].

\section{State of the art: Thermo physiological}

This chapter focuses on thermo-physiological properties of the human body and his dependence on clothing, which is the basis on the following measurements. Regarding the first law of thermodynamics (2-1): Heat production on the left hand side and the heat dissipation on the right hand side:

$$
\dot{\mathrm{H}}_{\mathrm{M}}+\dot{\mathrm{Q}}_{\mathrm{NIR}}=\dot{\mathrm{Q}}_{\mathrm{MIR}}+\dot{\mathrm{Q}}_{\mathrm{cd}}+\dot{\mathrm{Q}}_{\mathrm{cv}}+\dot{\mathrm{Q}}_{\mathrm{ev}}
$$

Heat production comes from enthalpy of reaction $\dot{H}_{M}$ through the metabolism or NIR-radiation $\dot{\mathrm{Q}}_{\mathrm{NIR}}(\lambda=3-50$ $\mu \mathrm{m}$ on average $10 \mu \mathrm{m}$ ) [13]. The heat dissipation depends on MIR-radiation $\dot{\mathrm{Q}}_{\mathrm{MIR}}$, conduction $\dot{\mathrm{Q}}_{\mathrm{cd}}$, convection $\dot{\mathrm{Q}}_{\mathrm{cv}}$ and evaporation $\dot{\mathrm{Q}}_{\mathrm{ev}}$.

The activity of the metabolism leads to heat formation $\dot{\mathrm{H}}_{M}$ inside the body. At low levels of activation, internal organs and the brain are the essential heat-generators. With higher activity the askeletal muscles have a higher impact on the heat production [14]. 
The Stefan-Boltzmann-Law describes thermal radiation like $\dot{\mathrm{Q}}_{\mathrm{NIR}}$ or $\dot{\mathrm{Q}}_{\mathrm{MIR}}$ :

$$
\dot{\mathrm{Q}}_{\mathrm{rad}}=\frac{2 \cdot \pi^{5} \cdot \mathrm{k}_{\mathrm{B}}^{4}}{15 \cdot \mathrm{h}^{3} \cdot \mathrm{c}^{2}} \cdot \varepsilon(\mathrm{T}) \cdot \mathrm{A} \cdot \mathrm{T}^{4}
$$

So the thermal radiation has a high dependence on the temperature of an object, but also on the emission and absorption of its surface $[\mathbf{1 5}, \mathbf{1 6}]$.

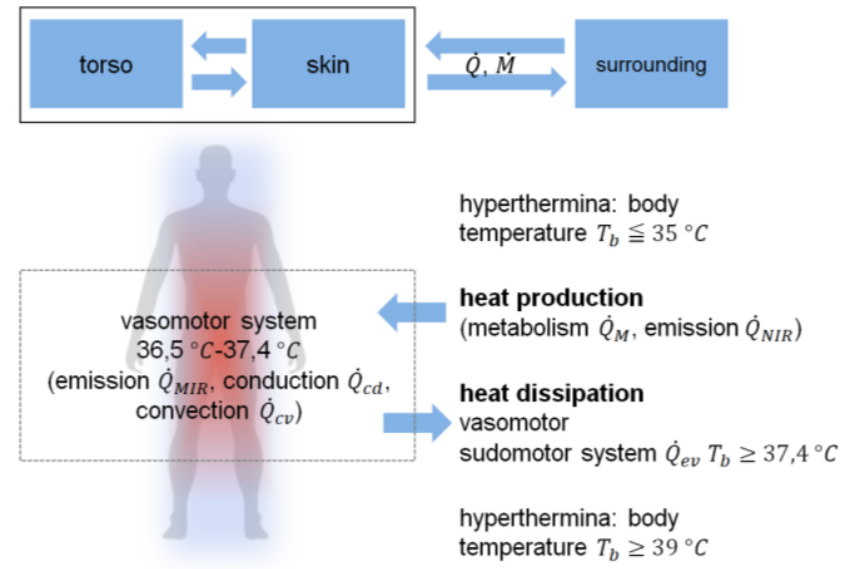

Fig. 1. Schematic figure of the human heat balance with heat production and heat dissipation [26].

Conduction and convection are the basis of the heat transport of our body. Conduction (heat dissipation over the skin) is proportional with the temperature gradient between the body surface and the surrounding and also with the thermal conductivity $\alpha$ of the interacting media. In contrast to water, air has a very low $\alpha$. That's why this mechanism increases with $2200 \%$ while sweating $[\mathbf{1 7 , 1 8}]$. Thermal conduction of solid materials depends on the molecular vibration. So natural and synthetic yarns have a thermal conduction between 0,04 and $0,5 \mathrm{~W} / \mathrm{m} * \mathrm{~K}[\mathbf{1 9}$, 20]. That is why this mechanism is relatively low.

Heat transportation with fluids in motion is called convection. The impact of this mechanism increases with the turbulent flow of the moving fluids, because the turbulence intensity reduces the thickness of the boundary layer. That's why forced convection has a much bigger impact on the thermal regulation than free convection $[\mathbf{2 0}$, 21].

Sweating on your skin enables the cooling mechanism of evaporation. The sweat which comes to the skin evaporates through the difference of water pressure between the skin and the environmental temperature [22]. The water pressure depends on temperature and relative humidity. Evaporation is possible if the vapour partial pressure of the skin is higher than the saturation pressure.

\section{Experimental}

The investigated structure always consists of a liquidcarrying layer, an air-carrying layer (15 $\mathrm{mm}$ high) with an integrated fan $\left(10 \mathrm{~m}^{3} / \mathrm{h}\right)$ and a top layer which can also contain a liquid-absorbing layer. Two different cooling systems were developed from these layers, one open and one closed configuration. The fan is always positioned to provide airflow in the air carrying layer. In both systems the forced convection through the fan is used to evaporate water from the humidified absorber. The energy for the phase change provides the appropriate evaporation cooling.
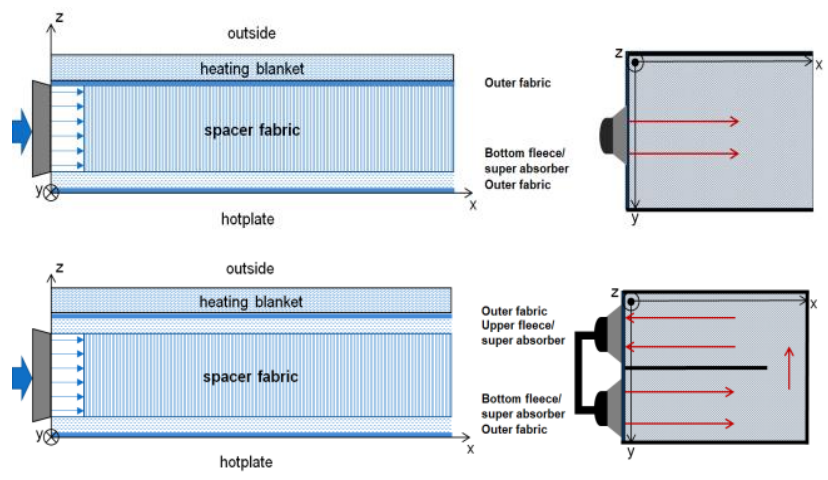

Fig. 2. Schematic description of the test setup (skin model and layering of the textile). The open layer structure in the top has no upper fleece / absorber, because the air with high humidity is transported out of the system. In the closed layer structure (bottom) the air is blown in a circle. The water should condense on the upper absorber.

In the open system the humid air is transported out of the system. In the closed system, the humid air should condense at the upper absorber. After reaching a state of equilibrium, the cooling effect of the closed system comes to a standstill.

For quantitative determination of thermo physiological parameters of clothing, there are a variety of measurement methods such as sweating manikins cylinders or hotplates) $[\mathbf{2 3 , 2 4}]$. The heat flow is determined. Under stationary test conditions the heat vapour resistance and the water vapour resistance in clothing are determined by the heating power through the textile to the environment.

To investigate the cooling effect of the layer structures, a measuring device for heat balancing was built $[25,26]$. The measuring device for heat balancing simulates the heat transfer from the human skin through the garment to the environment. For this purpose, an electrically heated measuring plate (MWB, Fig. 3) represents the human skin surface, which can be adjusted to a variable temperature level (skin temperature). In order to avoid heat loss, the measuring plate is surrounded by a frame, which is also electrically heated, and a base plate underneath heated to the same temperature level. The measuring device MWB is protected by a textile housing to avoid air currents or forced convection.

The measuring device allows a test surface of 240 $\mathrm{mm} * 240 \mathrm{~mm}$ to be kept at a constant temperature and measure the cooling effect of the layer structures. For this purpose, the layer structures are equipped with temperature and humidity sensors and placed on the measuring device. The test surface has as many pores as human skin: 121 per $\mathrm{cm}^{2}$ with a pore diameter of $400 \mu \mathrm{m}$. The hotplate can be operated in two different modes. On 


\section{Advanced Materials Letters www.vbripress.com/aml}

the one hand there is a temperature controlled mode where the power is recorded, on the other hand there is a power controlled mode where the temperature is documented.
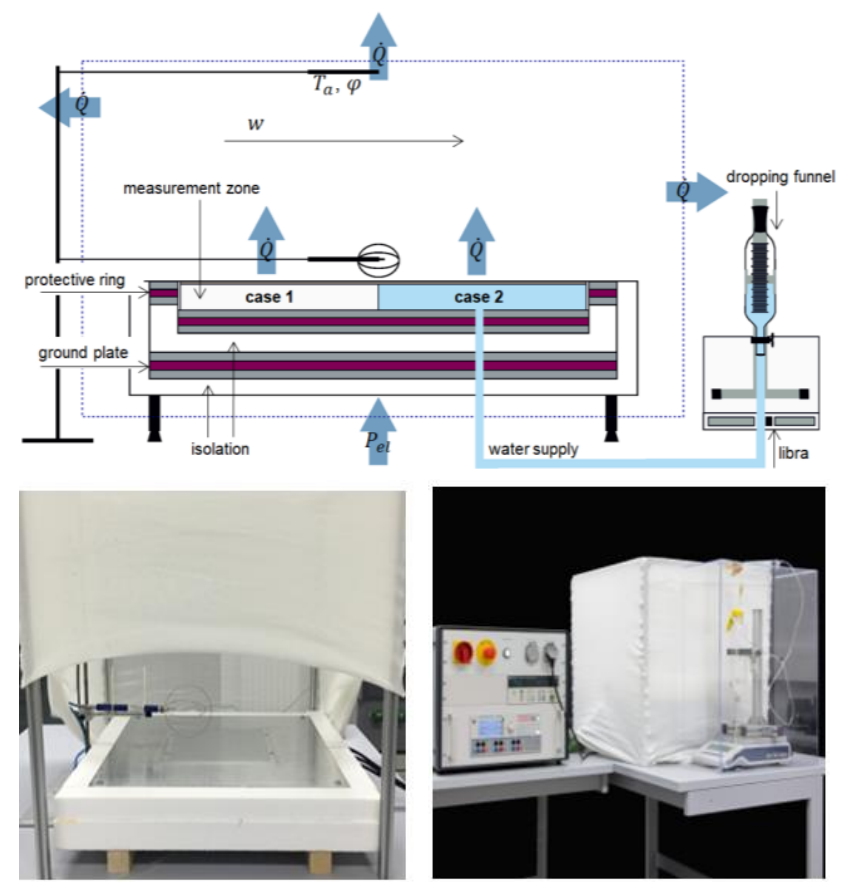

Fig. 3. Top: Schematic picture of the Hotplate measuring device (MWB). It is a proprietary development of the DITF Denkendorf based on the standard: ASTM D1518 "Standard Test Method for Thermal Resistance of Batting Systems Using a Hot Plate". Lower pictures: Photograph of the test system.

\section{Results and discussion}

In the first step, the liquid-bearing layer was examined. Four superabsorbent nonwoven materials and three viscose nonwovens without surface coating were selected. Each of them has a different basis weight (DIN EN 12127:1997-12). All nonwoven materials were tested for their water absorption capacity (DIN 53923:1978-01). The nonwovens with superabsorbents showed a significantly higher absorbency in terms of basis weight than the nonwovens without additional coating. The percentage improvement by the superabsorbents was approximately 200\% (Fig. 4).

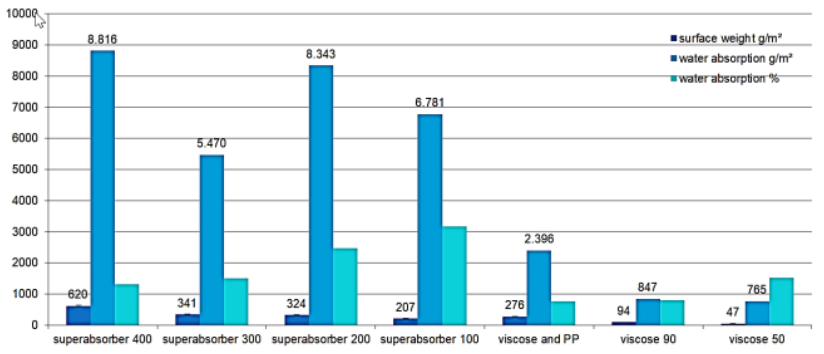

Fig. 4. The surface weight $\left(\mathrm{g} / \mathrm{m}^{2}\right)$, their ability to store water $\left(\mathrm{g} / \mathrm{m}^{2}\right)$ and the water absorption in percentage from the surface weight is shown. Nonwovens with a superabsorbents coating have a much higher potential to store liquid than nonwovens without a coating.
In a further step, the water distribution of the nonwoven materials during wetting was investigated (Fig. 5). The superabsorbents form long narrow channels which lead the water exclusively downwards when saturated. Nonwoven materials without superabsorbents show a significantly improved wetting behaviour. These investigations are also confirmed by the analysis of the rising kinetics of the nonwoven materials. The rise height of the nonwoven materials considerably exceeds the rise height of the superabsorbents.
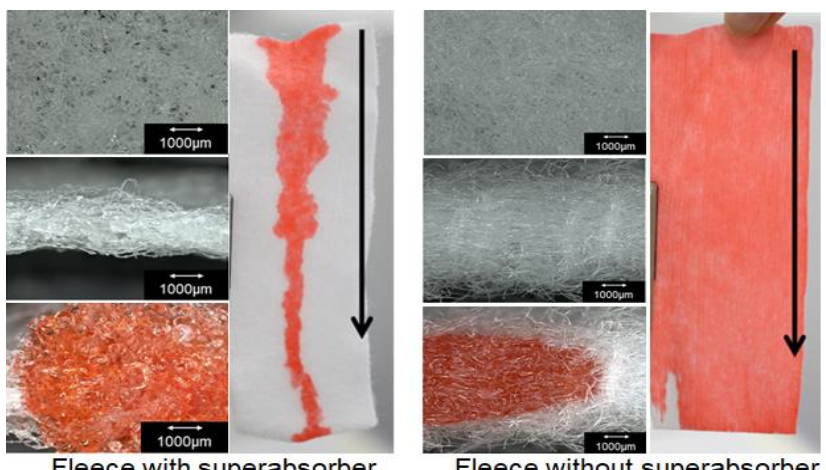

Fleece with superabsorbe

Fig. 5. Photographs of nonwovens with a superabsorbent coating form channels when water is addressed pointy. This makes it difficult to moisten the surface of clothing while it is being worn.

Secondly, the air-carrying layer was investigated. For this purpose, the air flow in the spacer fabric was examined with the aid of a high-speed camera and dyed particles (Fig. 6). The air flow inside the spacer fabric could be illustrated. The flow velocity through the textile was in parts more than $3 \mathrm{~m} / \mathrm{s}$. This allows a sufficient volume flow to be generated above the fleece.
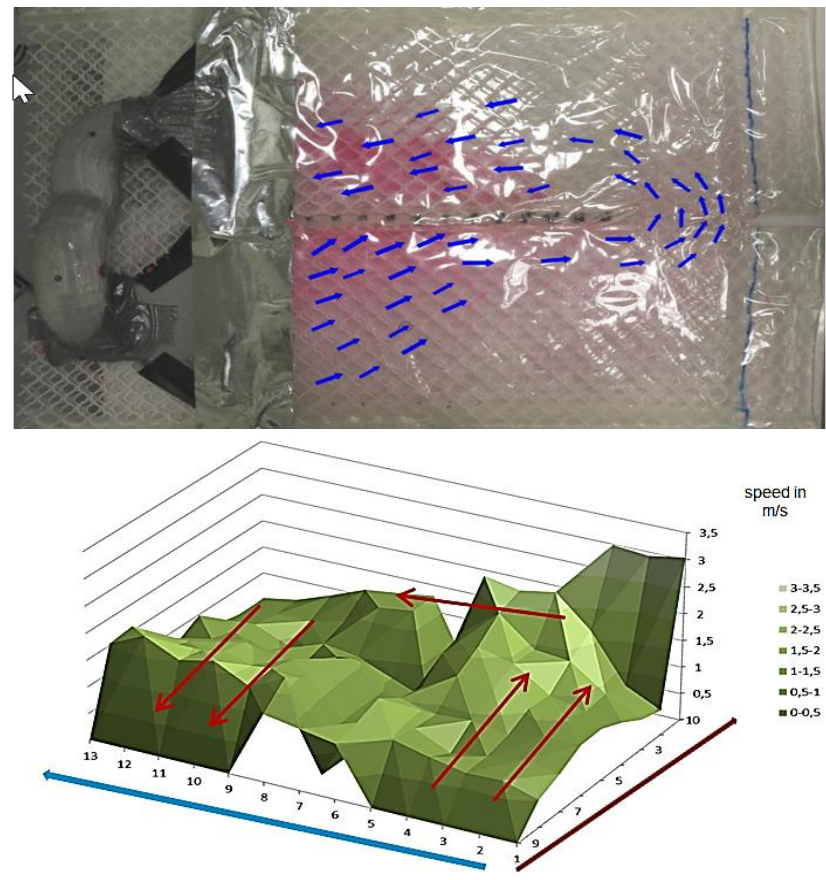

Fig. 6. Picture of the air flow velocity through the closed layer structure was in parts more than $3 \mathrm{~m} / \mathrm{s}$. This allows a sufficient volume flow to be generated above the fleece. 


\section{Advanced Materials Letters www.vbripress.com/aml}

Fig. 7a shows the cooling effect of the open layer structure. While the temperature of the outer layer rises, the inner fabric stays at a constant temperature. In both cooling systems, the system with uncoated fleece has a higher cooling effect than the system with superabsorbent fabric (Fig. 7b). This can be explained by the binding behaviour of the $\mathrm{H}_{2} \mathrm{O}$ molecules on the fleece. While superabsorbents form chemical bonds with the polar $\mathrm{H}_{2} \mathrm{O}$ molecules, these molecules are only bound by adhesion and capillary forces in the viscose fleece. Due to the lower binding energy of the adhesively bonded $\mathrm{H}_{2} \mathrm{O}$ molecules, they pass more easily into the gas phase. This results in evaporative cooling, which improves the cooling effect. This phenomenon was also observed in the investigation of warmer and colder water. Warmer water showed a better cooling effect than colder water. This was explained by the lower amount of energy required for the transition to the gas phase. Due to the low evaporation rates, the nonwovens with $50 \mathrm{ml}, 100 \mathrm{ml}$ and $150 \mathrm{ml}$ water on the inner textile show almost the same cooling properties. That is why the temperature on the inner and outer layer is almost the same on every sample (Fig. 7c).
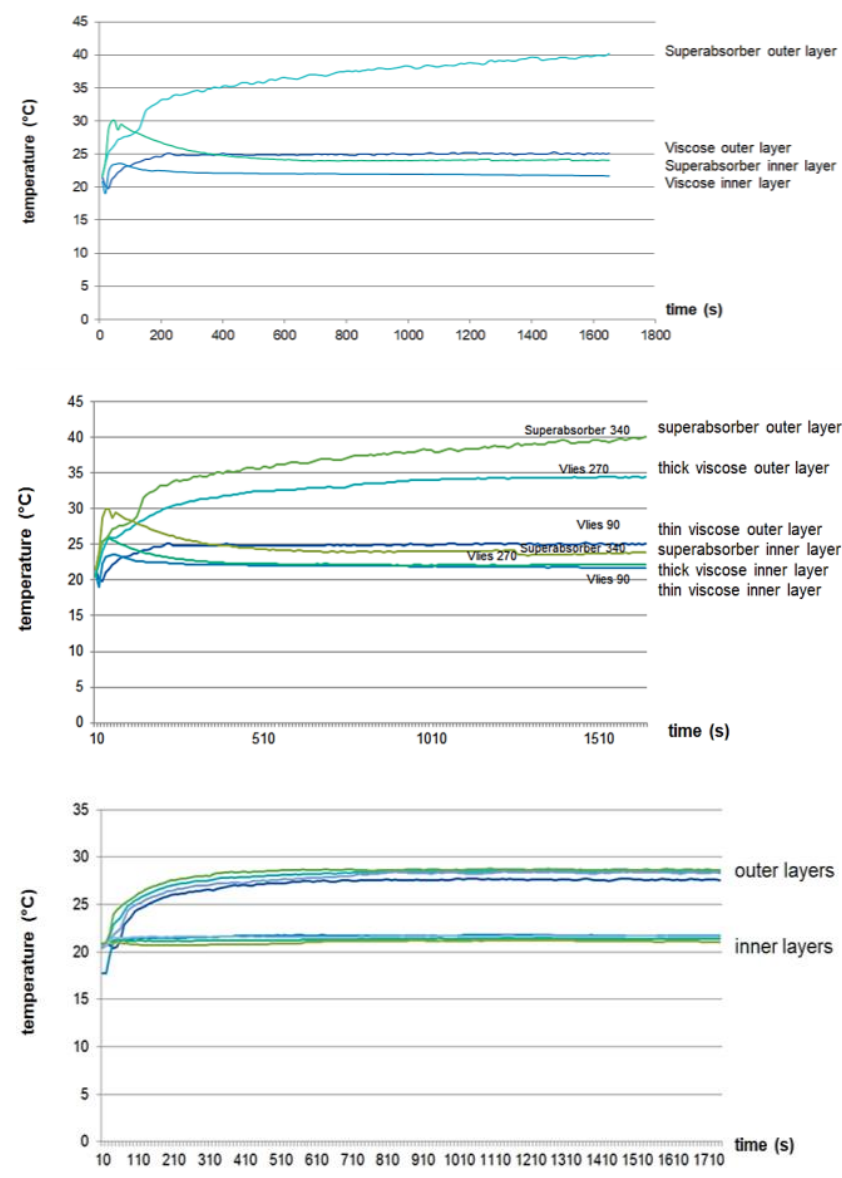

Fig. 7. (a) Open layer structure with outer textile and $100 \mathrm{ml}$ water on the inner textile $\left(32^{\circ} \mathrm{C}\right)$. (b) Open layer structure with outer textile and $100 \mathrm{ml}$ water on the inner textile $\left(32^{\circ} \mathrm{C}\right)$. (c) Open layer structure with outer textile and $50 \mathrm{ml}, 100 \mathrm{ml}$ and $150 \mathrm{ml}$ Water on the inner textile $\left(32^{\circ} \mathrm{C}\right)$.

\section{Conclusion}

Firefighters have to perform constantly under extreme environmental conditions, but their personal protective equipment impairs heat and sweat emission, so the body core temperature increases. That is why we have developed a textile cooling system based on evaporation. During several test methods we were able to show that viscose fleece can store less water than superabsorbent materials. However, the evaporation of the stored water is much better in viscose fleece. This allows a better cooling effect to be achieved. In addition, the absolute evaporation quantities are very low, so that the storage capacity of the viscose nonwovens is sufficient.

In the layer structure, both the open and the closed system have a sufficient cooling effect for a short period of 20 minutes, so that firefighters' operating times can be extended.

\section{Acknowledgements}

This research was supported German federal ministry for economic affairs and energy with their ZIM program. We thank our students Lisa Stöffler and Mara Wolter who provided insight and expertise that greatly assisted the research.

\section{Conflicts of interest}

There are no conflicts to declare

Keywords

Smart textiles, smart materials, superabsorbents, nonwovens.

Received: 06 March 2020

Revised: 21 April 2020

Accepted: 27 April 2020

\section{References}

1. Wenzel, H. G.; Piekarski, C.; "Klima und Arbeit," Bayerisches Staatministerium für Arbeit und Sozialordnung, München, 1982.

2. Mäkinen, H.; "Analysis of problem in the protection of fire fighters by personal protective equipment and clothing - development of a new turnout suit," Vantaa, Finland, 1991.

3. Schopper-Jochum, S.; Schubert, W.; Hocke, M.; "Vergleichende Bewertung des Trageverhaltens von Feuerwehreinsatzjacken (Phase I)," Arbeitsmedizin Sozialmedizin Umweltmedizin, 1997, pp. 138-144.

4. Haynes, H. J. G.; Molis, J. L.; "U.S. fire fighter injuries in 2014," National Fire Protection Association, 2015.

5. Kales, S. N.; Soteriades, E. S.; Christophi C. A.; Christiani; D. C.; The New England Journal of Medicine, 2007, 356, 1207.

6. R. Müller, Thermodynamik: Vom Tautropfen zum Solarkraftwerk, Walter de Gruyter, 2016.

7. Padova, T. D.; Wissenschaft im Strandkorb, Piper Verlag, 2009

8. Hohentein Institute.de/ Flyer: Cooling Power Next Generation Watson Testing, " [Online]. available:

https://www.hohenstein.com.tr/media/downloads/FC_Flyer_WATs on\%20Cooling\%20Power_EN_2015.pdf. [Zugriff am 1506 2019].

9. Claus Czeslik, H.S.R.W.; "Basiswissen Physikalische Chemie," Springer Verlag, 2008

10. Charles, U. M; Mortimer, E.; "Chemie: das Basiswissen der Chemie; 126 Tabellen," Georg Thieme Verlag, 2007.

11. Sheikhzadeh, M.M.Y. \&. M.; "Personal cooling garments: a review," The Journal of The Textile Institute, 2014.

12. Kothari, S.S. \& V.K.; Indian Journal of Fibre \& Textile Research 2013.

13. Vogel, H.; Gerthsen Physik, 19. Hrsg., Berlin: Springer-Verlag, 1997b, pp. 569-576. 


\section{Advanced}

14. Bauer, B.; Koch, S.; Mark, A.; Guarded-Hotplate measurements for heat transfer balancing, Tampere: Tampere University of Technology, ArcticPro - The Arctic Wear and Protection Research Network, The Swedish School of Textiles, University of Borås, Finnish Institute of Occupational Health, 2014.

15. Mutschler, E.; Schaible, H. G.; Vaupel, P.; Anatomie Physiologie Pathophysiologie des Menschen, Stuttgart: Wissenschaftliche Verlagsgesellschaft mbH, 2007, p. 859.

16. Jendritzky, G.; Mentz, G.; Schmidt-Kessen, H.; Schirmer, H.; Methodik zur räumlichen Bewertung der thermischen Komponente im Bioklima des Menschen, Hannover: Akademie für Raumforschung und Landesplanung, 1990.

17. Mutschler, E.; Schaible, H.G.; Vaupel, P.; Anatomie Physiologie Pathophysiologie des Menschen, 6 Hrsg., Stuttgart: Wissenschaftliche Verlagsgesellschaft mbH, 2007, 521-526.

18. Rein, H.; Einführung in die Physiologie des Menschen, Berlin: Springer-Verlag, 1948.

19. Xu, D.; Chen, Y.; Zhou, X.; International Journal of Heat and Mass Transfer, 2013, 60, 582.

20. Vogel, H.; Gerthsen Physik, 19 Hrsg., Berlin: Springer-Verlag, 1997, pp. 232-292.

21. ANSI/ASHRAE55, Thermal and Environmental Conditions for Human Occupancy, Atlanta: The American Society of Heating, Refrigerating, and Air-Conditioning Engineers, Inc., 2010.

22. Hensel, H.; "Temperaturregulation," in Lehrbuch der Physiologie, Stuttgart, Thieme-Verlag, 1973, pp. 224-235.

23. Holmér, I.; European Journal of Applied Physiology, 2004, 92, 614.

24. Mc Cullough, E.; Huang, J.; Kim, C.; Journal of ASTM International, 2004, 1, 121.

25. Mark, A.; Development of a measurement device investigating thermodynamic properties on clothing textiles, ITV Denkendorf: Universität Stuttgart, Studienarbeit, 2017.

26. Mark et al., Artificial skin for sweating guarded hotplates and manikins based on weft knitted fabrics, Textile Research Journal, 2018.

\section{Authors' biography}

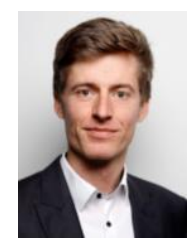

Sebastian Micus M.Sc. studied mechanical engineering and management at the Technical University of Munich (TUM). Since 2017 he works as a research assistant at the German Institutes for Textile and Fiber Research (DITF) in the department E-Textiles, automation and acoustics. 